\title{
Research on the Division of Small Layers of the Yan'an Group in the Western District of Mahuang Mountain
}

\author{
Dongxu Fan, Shucheng Tan* \\ Yunnan University, Kunming, China \\ Email: fdx312@126.com, *shchtan@ynu.edu.cn
}

How to cite this paper: Fan, D.X. and Tan, S.C. (2021) Research on the Division of Small Layers of the Yan'an Group in the Western District of Mahuang Mountain. Open Journal of Yangtze Gas and Oil, 6, 175-190.

https://doi.org/10.4236/ojogas.2021.64015

Received: August 31, 2021

Accepted: October 25, 2021

Published: October 28, 2021

Copyright $\odot 2021$ by author(s) and Scientific Research Publishing Inc. This work is licensed under the Creative Commons Attribution International License (CC BY 4.0).

http://creativecommons.org/licenses/by/4.0/

\begin{abstract}
To supplement, adjust and improve the division plan of crude oil strata in the west of Mahuangshan Mountain. Combining well logging, core, and drilling analysis and testing data, Petrel software was utilized to classify and compare the 10 layers of the Yan'an Formation. Draw 6 "net-like" skeleton profiles for Ningdong No. 2 and No. 3 wells, involving 31 wells. On the basis of the large-layer strata division, Yan 8 and Yan 9 sections are divided and compared; five "net-like" skeleton profiles were drawn in the 5 well, involving 16 wells. On the basis of the large-layer division, the small-layer division and comparison were performed by Yan 8 and Yan 9. The results show that the Yan 8 oil layer is divided into two stratigraphic units, and Yan 8 and Yan 82, and the Yan 9 oil layer is divided into two stratigraphic units, Yan 91 and Yan 92; the Yan 2 layer in the 2 and 3 well blocks of Ningdong is in the marker layer. The top of the coal seam, Yan 8 layers in the Ningdong 5 well area is on the top of the auxiliary marker seam. The fine division of small layers into tiny layers of sedimentary microfacies, reservoir heterogeneity, development dynamic analysis, remaining oil distribution and other studies provide indispensable data.
\end{abstract}

\section{Keywords}

Small Layer, Small Layer Division, Small Layer Contrast

\section{Introduction}

The western area of Mahuangshan is located on the western edge of the Ordos Basin. From the 1950s to the 1980s, Changqing and additional oil exploration departments successively carried out large-scale oil exploration in the area [1]. The drilling revealed that the Jurassic Yan'an formation of the target layer is 
about 2000 - $2400 \mathrm{~m}$ deep and $270-380 \mathrm{~m}$ thick. It is a set of coal and oil-bearing stratum combination dominated by river swamp facies. According to the lithology change, sedimentary cycle, oil-bearing property and coal seam development characteristics, the Yan'an formation is divided into four sections and 10 oil-bearing groups from bottom to top. They are the first section Yan 10 and Yan 9, the second section Yan 8, Yan 7 and Yan 6, the third section Yan 5 and Yan 4, and the fourth section Yan 3, Yan 2 and Yan 1 oil-bearing groups. Most of the oil-bearing groups are capped by coal stratum. Because the "oil sand bodies" of fluvial sand bodies often exist in the form of "small-layer complexes", based on this understanding, the sedimentary time unit can be further subdivided on the basis of the original sand body division of the Ningdong Oilfield, that is, "Small layers" in order to achieve the purpose of fine reservoir description, which will have an important guiding role for future oilfield development in this area.

The Mahuangshanxi fault block is situated on the west side of the middle section of the Tianhuan syncline in the Ordos Basin [2]. The west side of the fault block is the intersection of the middle section of the Majiatan section and the middle section of the Tianhuan syncline [3]. In the middle of the Yanshan Movement, the structural belt experienced strong compression and shearing, forming the basic characteristics of the thrust structure west of the structural belt [4]. During the Himalayas, the western edge thrust belt changed to a certain extent, extending from south to north and consisting of multiple main thrust faults. The secondary fault block anticline affected by the fault plays a significant role in controlling the migration and accumulation of oil and gas. The local structures are mainly anticlines, fault blocks and nose structures [5]. However, the deep structures are quite small, generally large and gentle anticlines. Faults, local anticlines and fault nose structures are developed and distributed in stratigraphic belts, forming favorable hydrocarbon accumulation belts. So far, more than 10 oil fields have been discovered in this area. Except for Majiatan, which is a Triassic basin, the rest are Jurassic basins [6].

\section{Filed Characteristics}

\subsection{Selection of Marker Layer}

Identification and comparison of sedimentary marker layers are of great significance. In order to ensure that there is no "string layer" or error in the comparison of sand layer groups, the sign layer must be mastered [7]. The so-called sign layer refers to the stable regional distribution, with a certain distribution range and thickness, lithology, electricity. The characteristics are observable, easy to identify, and there are fixed layers in the profile, which is convenient for lateral tracking and comparison. Coal seam or stable mudstone is generally selected as the marker layer. In stratigraphic correlation, the marker layer is very important. The more marker layers, the easier and more accurate the profile is. In the specific stratigraphic division and comparison, the main marker layer and the aux- 
iliary marker layer can be selected, with both primary and secondary consideration and comprehensive application.

In addition, the change of sedimentary cycle or sedimentary rhythm in the sedimentary sequence is the basic guiding ideology for division and comparison. The main principles to be considered when dividing and contrasting small layers are as follows:

1) We fully considered the sedimentary events or the development of small sand layers in the same sand layer group in our research, and then determined the number of small sand layers that can be identified in most oil wells.

2) According to the characteristics of each small layer of a sand layer group, the change sequence usually includes three types: upward coarsening type, upward fining type and sand mud interlayer type.

3) When comparing small sand layers, if the corresponding sand layers are not developed, the treatment shall be carried out in accordance with the principle of elementary isochronous deposition events and simultaneous phase deposition. For example, if the corresponding sand phase becomes mudstone, it can be considered to "split" according to the thickness ratio.

\subsection{Selection of Standard Wells}

The selection principles of standard wells are as follows:

1) The standard well is preferably a vertical well that is conducive to the structural site, with no faults passing through to prevent formation loss and duplication;

2) The standard well should be the most complete well drilled into the formation; otherwise the stratigraphic sequence is incomplete and unrepresentative;

3) Standard wells must have good borehole conditions, normal mud and high-quality logging data;

4) Standard wells shall have drill pipe and cable test data;

5) Standard wells should have certain coring footage and complete analytical and laboratory data.

\subsection{Division and Comparison of Small Layers}

In this study, the combination of well, core and drill analysis and testing data [8] [9] [10], Petrel software was used to establish 6 comparison profiles (Figures 3-8) and 6 comparison lines in Ningdong 2 and 3 well areas of Ningdong Oilfield for analysis (Table 1, Figure 1); 5 comparison profiles (Figures 9-13) and 5 comparison lines were established for analysis in Ningdong 5 well areas of Ningdong Oilfield (Table 2, Figure 2); draw 6 comparison profiles for Ningdong 2 and 3 well areas of Ningdong Oilfield, and use the top boundary of 1 as the standard to flatten, and divide and compare the 1 - 10 large layers of extension; for Ningdong 5 well areas, draw 5 comparison profiles, on the basis of large layer division and comparison, the Ningdong 2, 3 well area extension 8, extension 9 oil layer and Ningdong 5 well area extension 8, extension 9 oil layer for small layer division comparison (Table 3). 


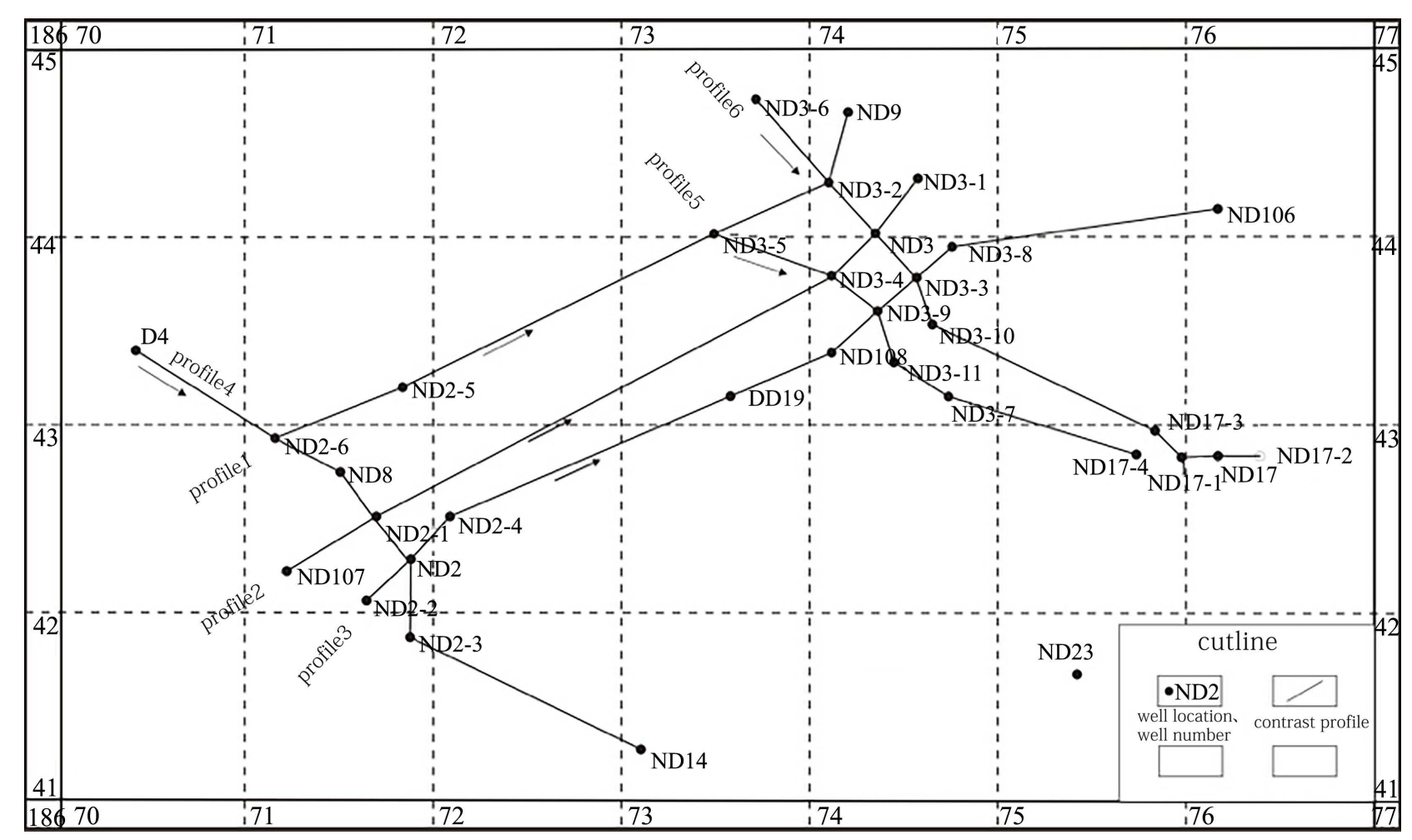

Figure 1. Stratigraphic division and comparison profile location map of Ningdong well areas 2 and 3.

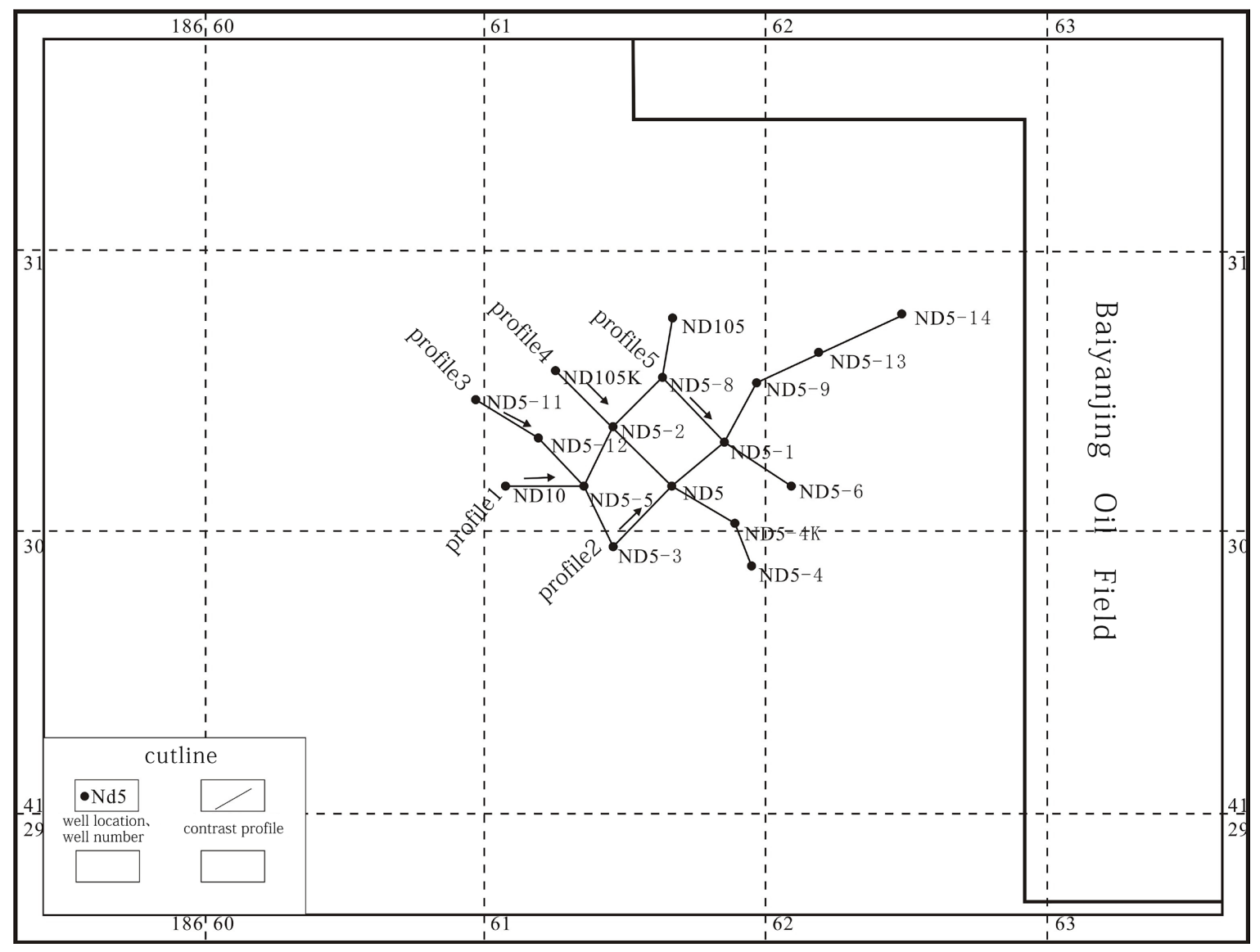

Figure 2. Stratigraphic division comparison profile location map of Ningdong 5 well area. 
Table 1. Contrast profile of Ningdong wells 2 and 3.

\begin{tabular}{cc}
\hline Profile1 & ND2-6-ND2-5-ND3-5-ND3-2-ND9 \\
Profile2 & ND107-ND2-1-ND3-4-ND3-ND3-1 \\
Profile3 & ND2-2-ND2-ND2-4-DD19-ND108-ND3-9-ND3-3-ND3-8-ND106 \\
Profile4 & D4-ND2-6-ND8-ND2-1-ND2-ND2-3-ND14 \\
Profile5 & ND3-5-ND3-4-ND3-9-ND3-11-ND3-7-ND17-4 \\
Profile6 & ND3-6-ND3-2-ND3-ND3-3-ND3-10-ND17-3-ND17-ND17-2 \\
\hline
\end{tabular}

Table 2. Ningdong 5 well area contrast profile.

\begin{tabular}{cc}
\hline Profile1 & ND10-ND5-5-ND5-2-ND5-8-ND105 \\
Profile2 & ND5-3-ND5-ND5-1-ND5-9-ND5-13-ND5-14 \\
Profile3 & ND5-11-ND5-12-ND5-5-ND5-3 \\
Profile4 & ND105K-ND5-2-ND5-ND5-4K-ND5-4 \\
Profile5 & ND5-8-ND5-1-ND5-6 \\
\hline
\end{tabular}

Table 3. Subdivision results of Yan'an group extension 8 and extension 9 oil groups.

\begin{tabular}{ccc}
\hline Group & Oil group & Small layer \\
\hline \multirow{2}{*}{ Yan'an Group } & Yan8 & Yan81 \\
& & Yan82 \\
& Yan9 & Yan91 \\
& & Yan92 \\
\hline
\end{tabular}

1) Ningdong 2, 3 well area small layer division contrast profile

The following is a small-layer division comparison profile of 6 sections in Ningdong 2 and 3 well areas (Figures 3-10).

2) Ningdong 5 well area small layer division contrast profile

Combined with the river direction and the spread of the sand body, all wells in the Ningdong 5 well area are divided into five comparative profiles, the following is a comparative profile of the four small layers of Yan 81, Yan 82, Yan 91 and Yan 92 (Figures 9-13).

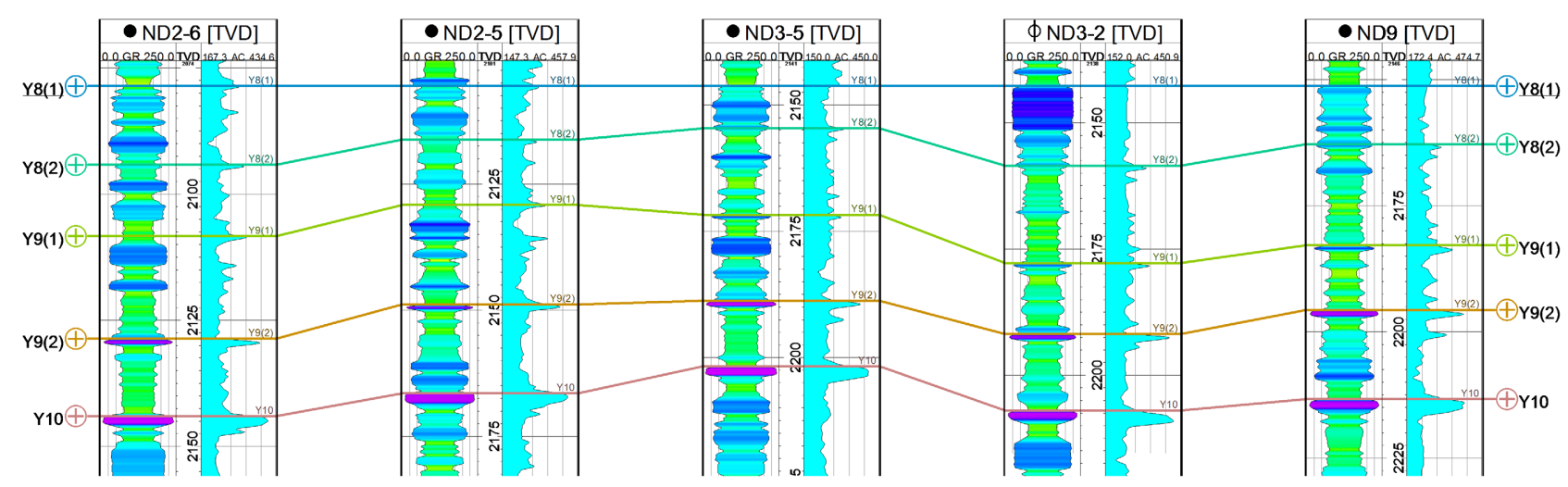

Figure 3. Comparison Section 1 of Yan'an group Yan 8 and 9 small layers in Ningdong well areas 2 and 3. 


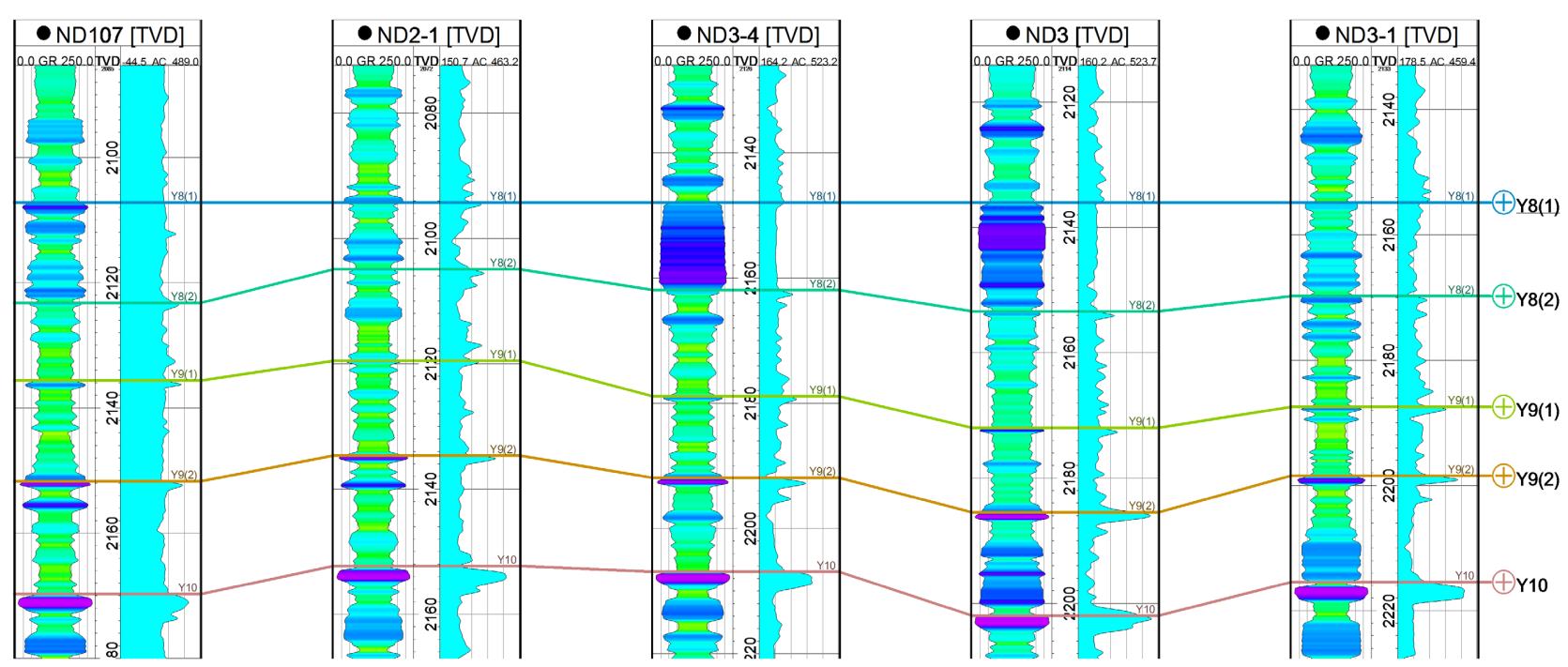

Figure 4. Contrast Section 2 of Yan'an group Yan 8 and 9 small layers in Ningdong well areas 2 and 3.

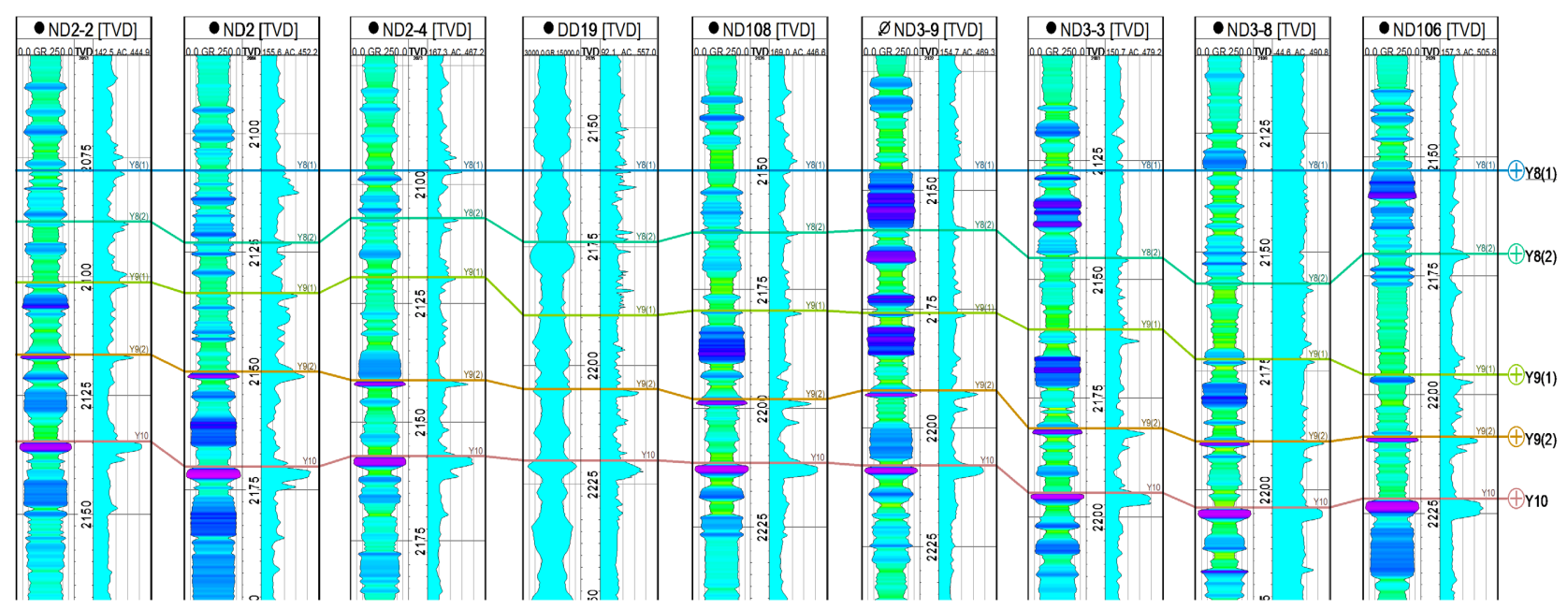

Figure 5. Comparison Section 3 of Yan'an group Yan 8 and 9 small layers in Ningdong well areas 2 and 3.

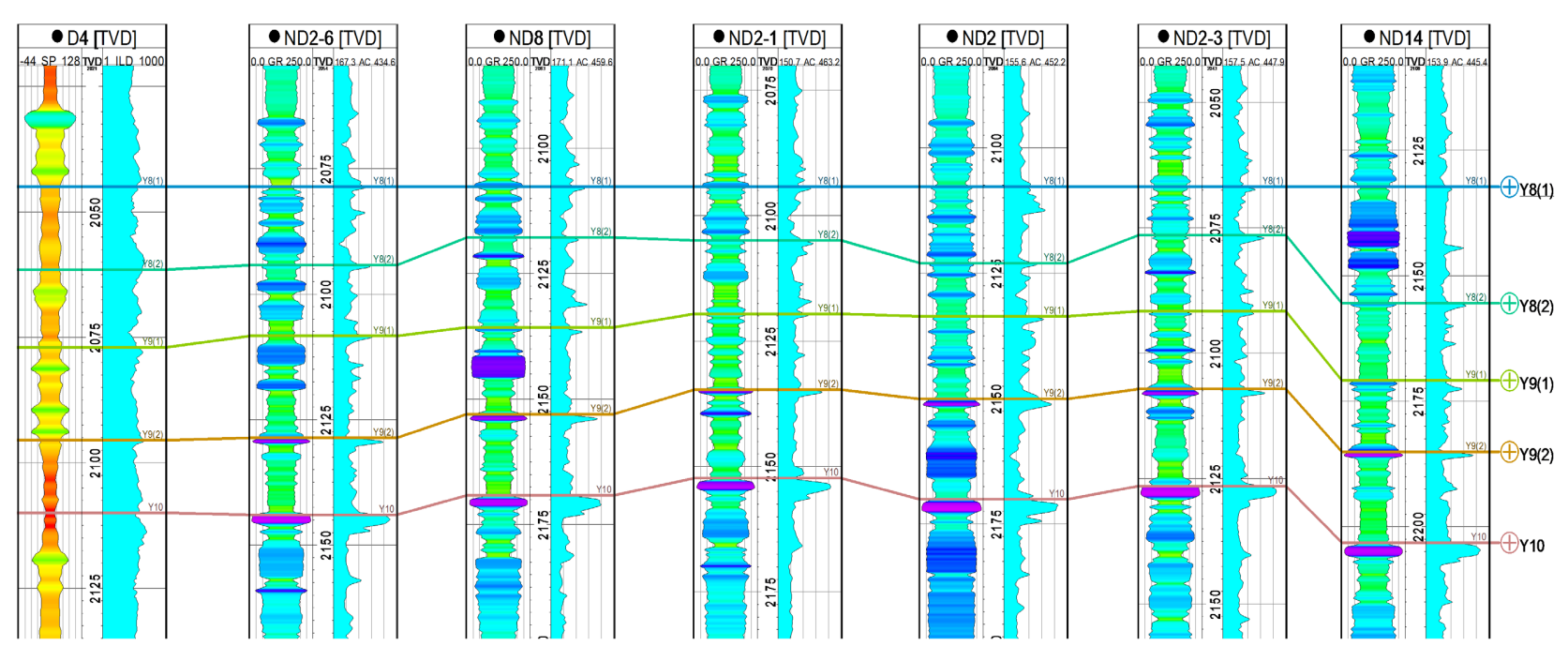

Figure 6. Comparison Section 4 of small layers of Yan'an group Yan 8 and 9 in Ningdong well areas 2 and 3. 


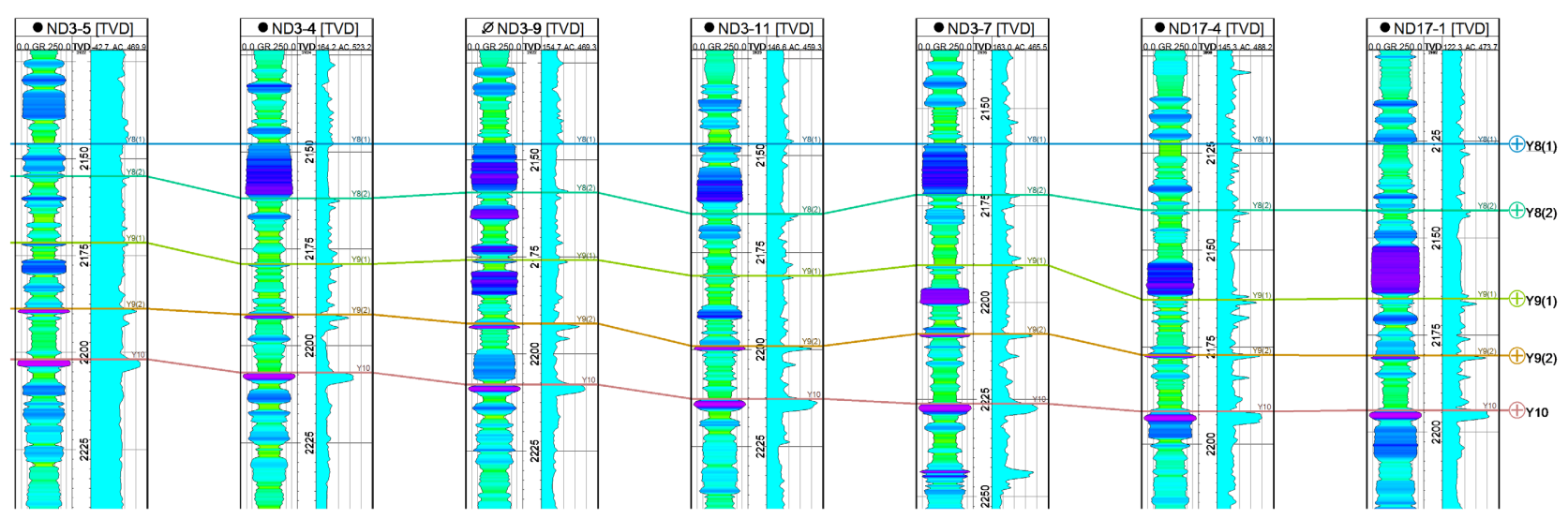

Figure 7. Comparison Section 5 of small layers of Yan'an group Yan 8 and 9 in Ningdong well areas 2 and 3.

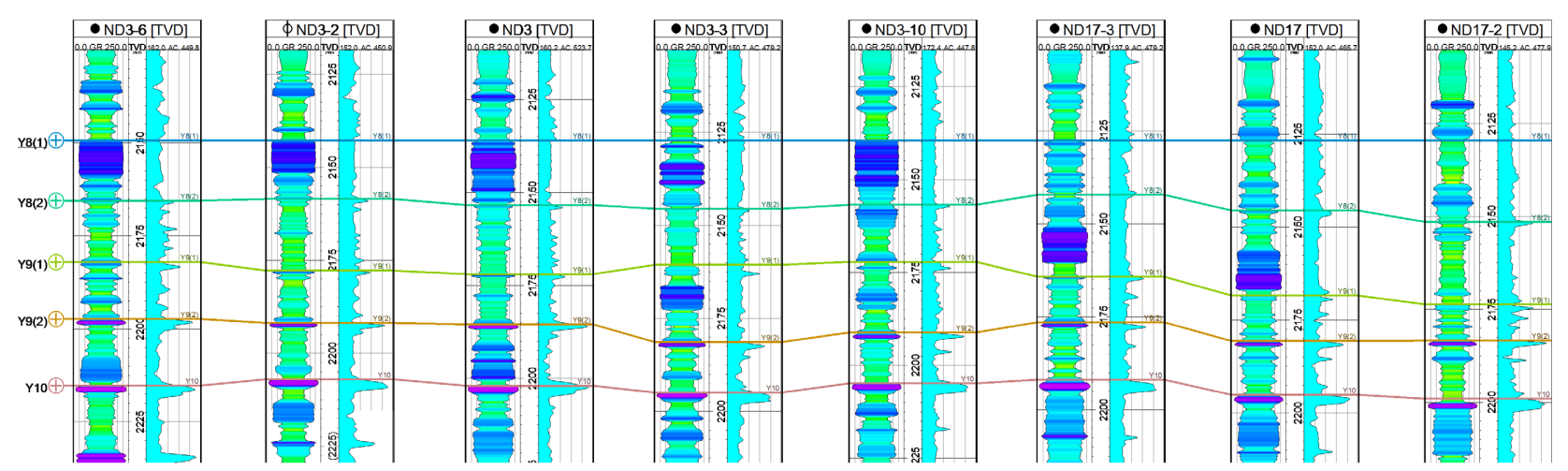

Figure 8. Comparison Section 6 of small layers of Yan'an group Yan 8 and 9 in Ningdong well areas 2 and 3.

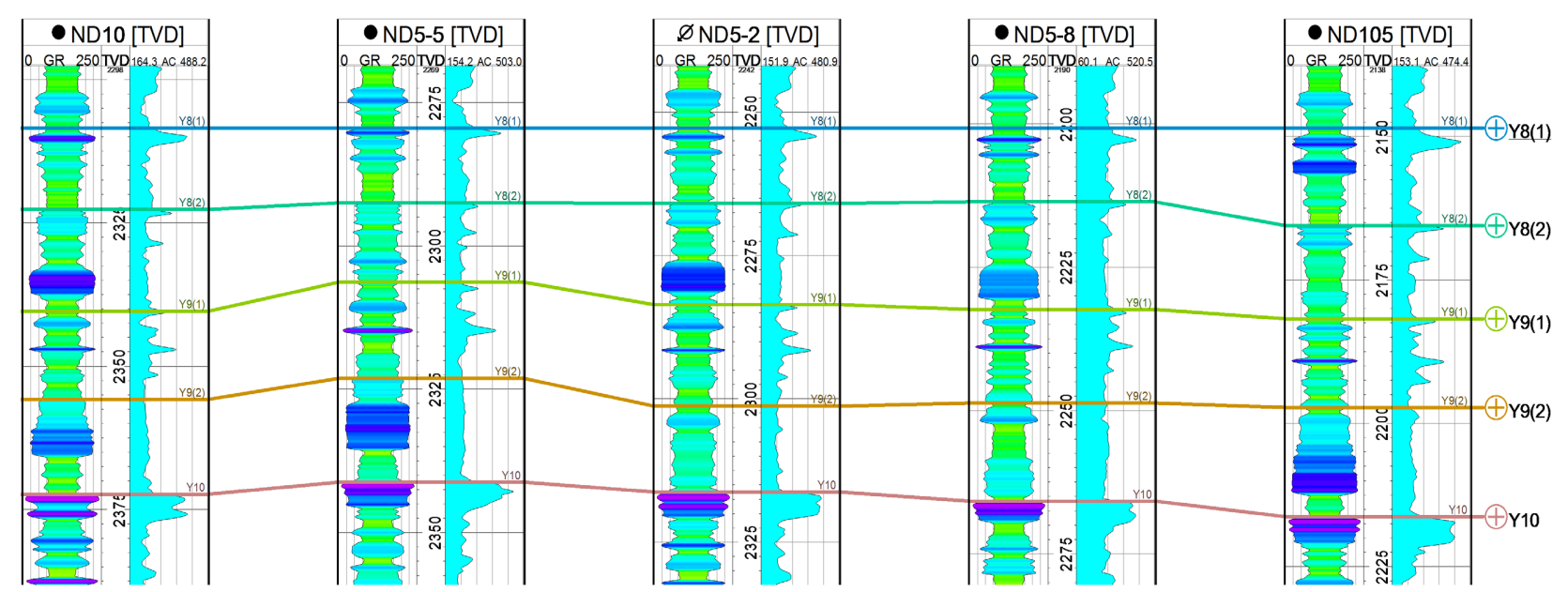

Figure 9. Yan'an group Yan 8 and 9 small layers in Ningdong well area are divided into comparative Section 1.

\section{Results}

\subsection{Determination of Marker Layer}

There are 4 obvious marker layers in the whole area (Figure 14):

Yan 2: gray-brown, gray-green toner-fine sandstone, mudstone, shale interlayer, sand layer locally thickened [11]. The top coal seam is thicker and most wells can be compared, and the distribution is wide and stable. The electrical 


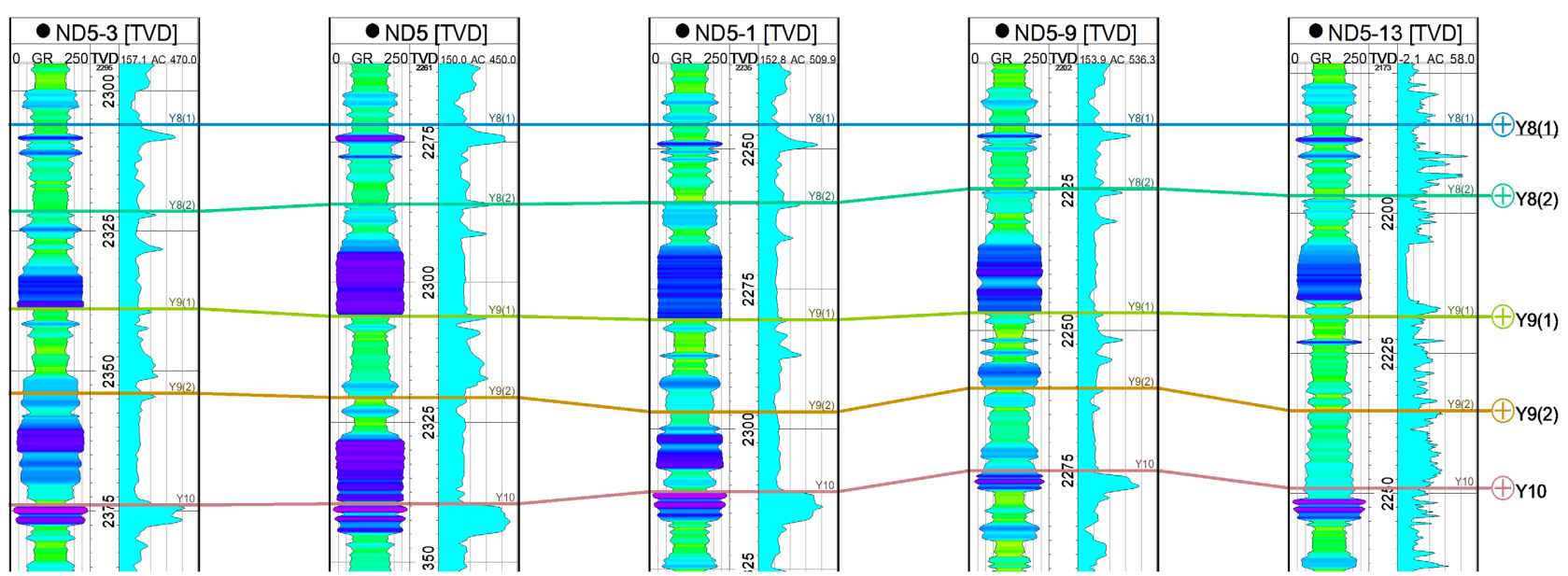

Figure 10. Comparison Section 2 of small layers of Yan'an group extensions 8 and 9 in Ningdong well area 5.

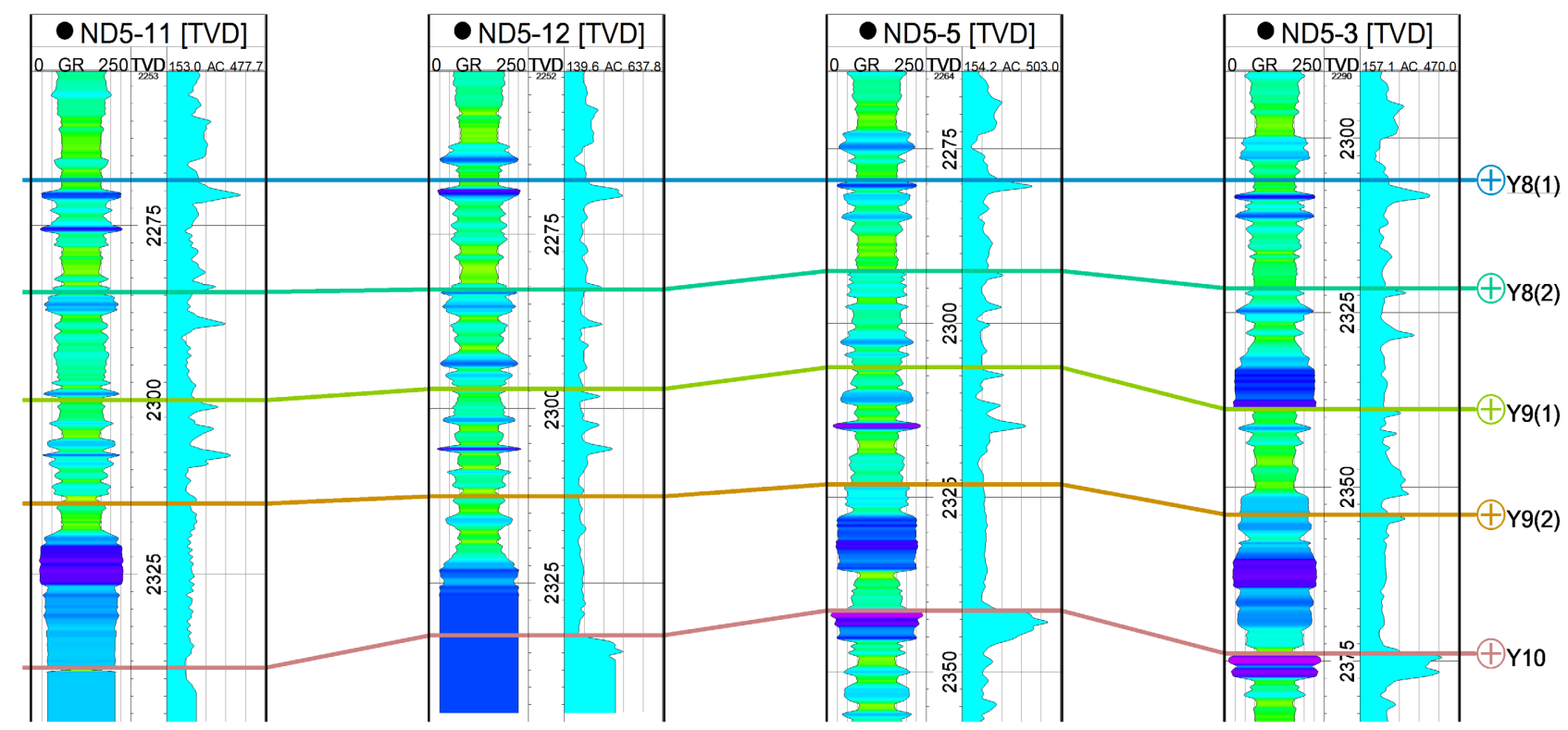

Figure 11. Comparison Section 3 of Yan'an group extension 8 and 9 small layers in Ningdong well area 5.

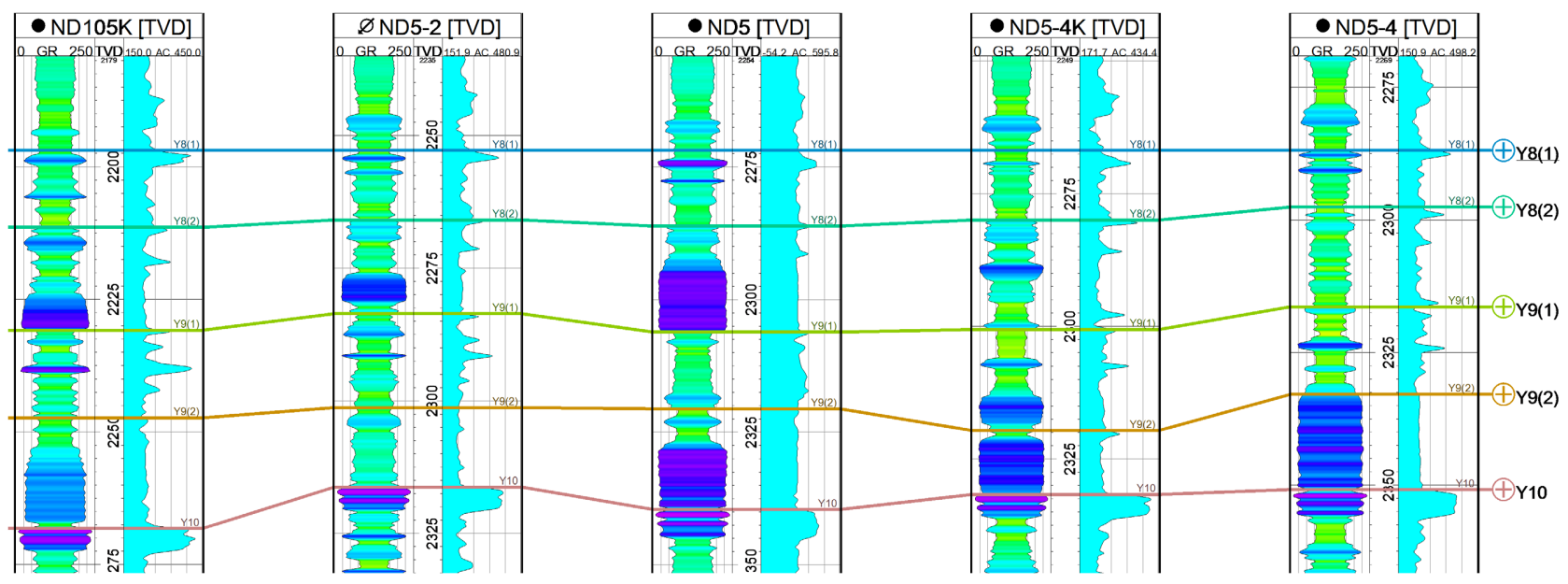

Figure 12. Yan'an group Yan 8 and 9 small layers in Ningdong 5 well area are divided into comparative Section 4. 


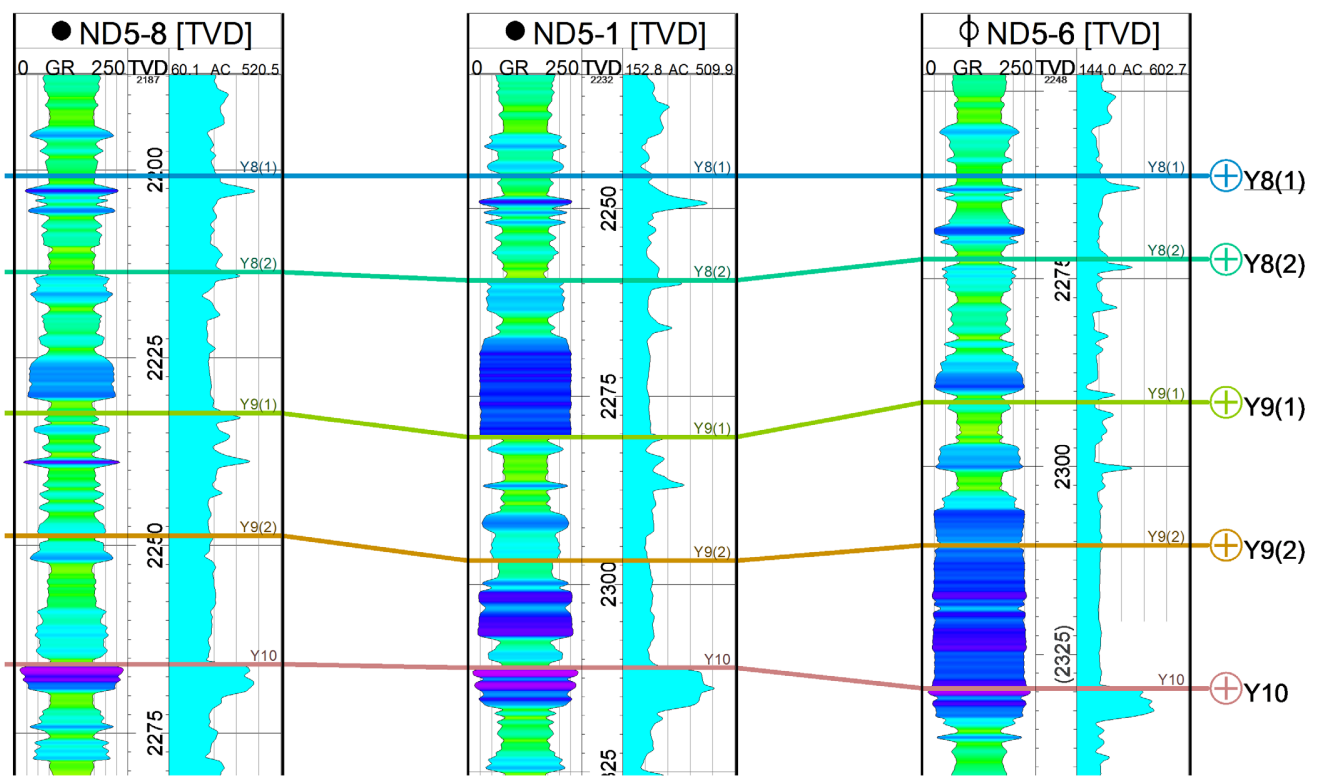

Figure 13. Yan'an group Yan 8 and 9 small layers in Ningdong well area are divided into comparative Section 5.

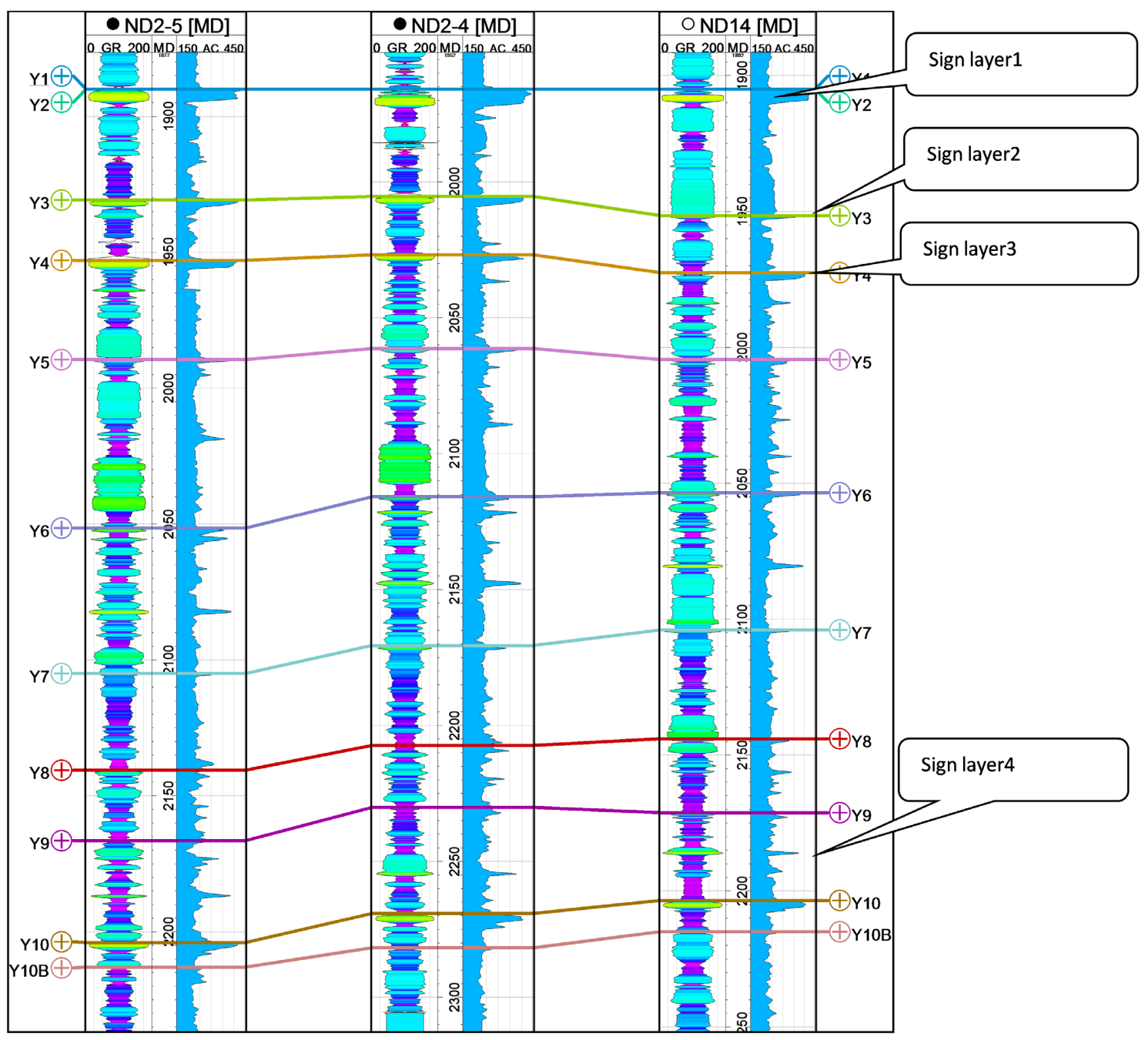

Figure 14. Location map of reservoir stratified marker layer of Yan'an group in Ningdong Oilfield. 
characteristics of the top coal seam are obvious. The characteristics of finger-like natural gamma low value, finger-like low-density value, finger-like resistivity high value, finger-like high-amplitude acoustic wave time difference high value and well diameter expansion are easy to identify and stable distribution in the whole area. It is the most obvious sign layer in the whole region, which is sign layer 1 .

Yan 3: gray-white fine, siltstone with coal seam and black carbonaceous mudstone. The electrical characteristics of the top coal seam are more obvious, natural gamma low value, low density, high resistivity value, the high value of acoustic time difference, high neutron, stable distribution in the whole area, for the marker layer 2.

Yan $4+5$ : It is a relatively fine layer group in the Yan'an Formation. The upper part is gray, gray-black shale, and carbonaceous shale, with gray and gray-white siltstone, and the lower part is coarsened into gray-white fine sandstone, with gray, gray-black silty mudstone, mudstone and shale. The electrical characteristics of the top coal seam of Yan 4 are more obvious, with low natural gamma value, low density, high resistivity value, high acoustic time difference value, high neutron, stable distribution in the whole area, and mark layer 3;

Yan 10: A set of widely distributed "pagoda-shaped sandstone" has been developed, and the electrical characteristics of the top coal seam are more obvious, natural gamma low value, low density, high resistivity value, high acoustic time difference value, High neutrons, stable distribution in the whole area, marking layer 4; this group of strata and the underlying extension group are pseudo-integrated contact relationship.

In the subdivision contrast extension 8 -extension 9 , in addition to considering the marker layer, but also select a certain thickness of stable mudstone section or stable coal seam as the auxiliary marker layer of each small layer.

\subsection{Determination of Standard Wells}

Through systematic analysis, ND2 well has complete formation and complete logging data and analysis and laboratory data. Therefore, in Ningdong oil field Ningdong 2, 3 well and Ningdong 5 well area stratigraphic division comparison, select ND2 well as the standard well (Figure 15 and Figure 16).

\subsection{Comparison Results of Small Layer Division}

The above-mentioned marker layer and the auxiliary marker layer are used as the main control framework, and each layer is divided and compared according to the cyclicity of sedimentary evolution. This division compares the top boundaries of Yan 1, Yan 2, Yan 3, Yan 4 + 5, Yan 6, Yan 7, Yan81, Yan 82, Yan 91, Yan 92, Yan10 and the bottom boundary of extension 10. Among them, Yan 8 and Yan 9 oil layer groups are subdivided into four small layers of Yan 81, 82 and Yan 91 and 92 on the basis of the original stratification [12], and the comparison results are shown in Table 4 and Table 5. 


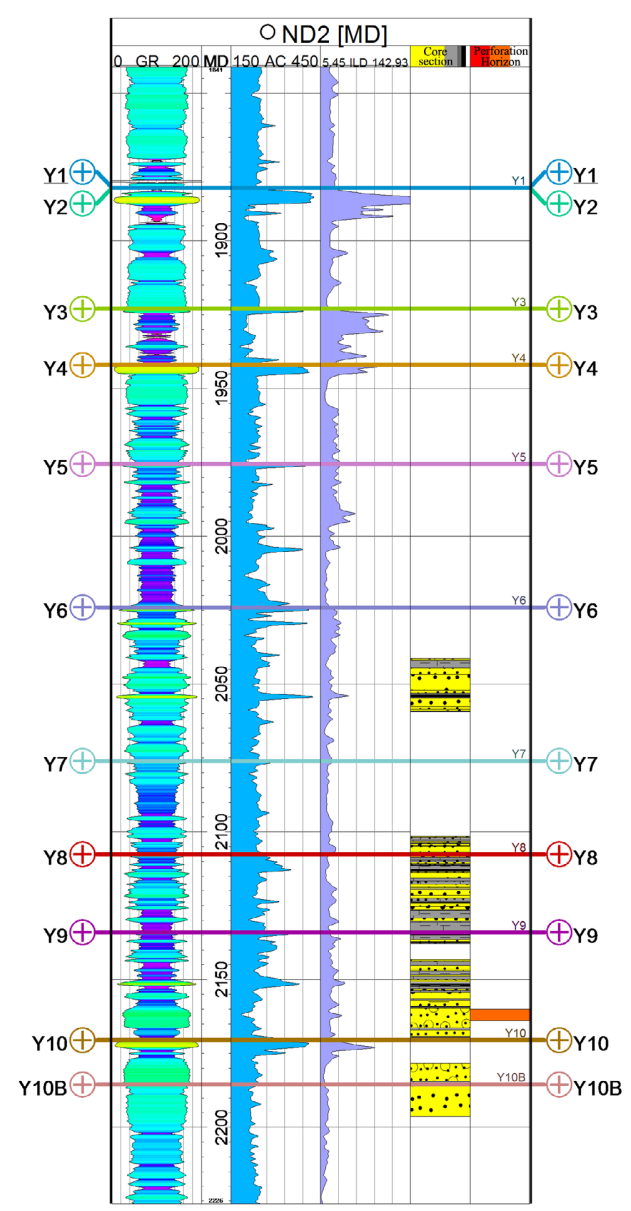

Figure 15. Large layer division results of Ningdong 2 well.

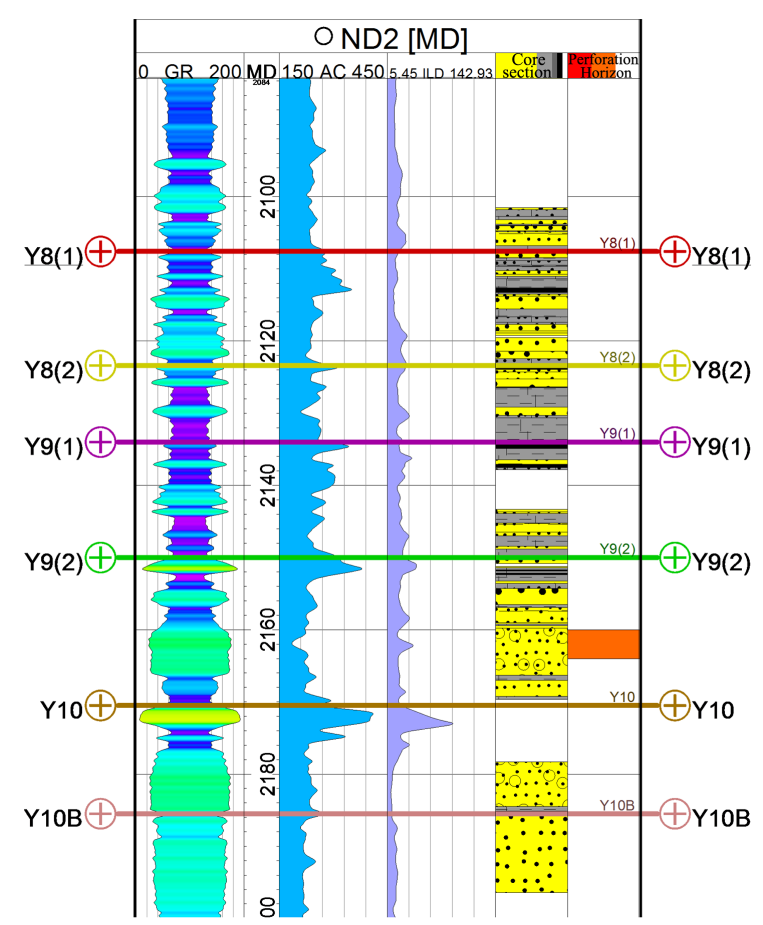

Figure 16. Division results of small layers in Ningdong 2 well. 
Table 4. Comparison results of small layer division of Yan 8 and Yan 9 in Ningdong 2 and 3 well areas.

\begin{tabular}{|c|c|c|c|c|c|c|c|c|}
\hline \multirow{2}{*}{ Position } & $\begin{array}{c}\text { Ning } \\
4\end{array}$ & $\begin{array}{c}\text { Ningdong } \\
19\end{array}$ & $\begin{array}{l}\text { Ningdong } \\
2\end{array}$ & $\begin{array}{c}\text { Ningdong } \\
8\end{array}$ & $\begin{array}{c}\text { Ningdong } \\
14\end{array}$ & $\begin{array}{c}\text { Ningdong } \\
107\end{array}$ & $\begin{array}{c}\text { Ningdong } \\
2-1\end{array}$ & $\begin{array}{c}\text { Ningdong } \\
2-2\end{array}$ \\
\hline & $\begin{array}{c}\text { Head } \\
\text { depth }(m)\end{array}$ & $\begin{array}{c}\text { Head } \\
\text { depth }(m)\end{array}$ & $\begin{array}{c}\text { Head } \\
\text { depth }(\mathrm{m})\end{array}$ & $\begin{array}{c}\text { Head } \\
\text { depth }(m)\end{array}$ & $\begin{array}{c}\text { Head } \\
\text { depth }(m)\end{array}$ & $\begin{array}{c}\text { Head } \\
\text { depth }(\mathrm{m})\end{array}$ & $\begin{array}{c}\text { Head } \\
\text { depth }(\mathrm{m})\end{array}$ & $\begin{array}{c}\text { Head } \\
\text { depth }(\mathrm{m})\end{array}$ \\
\hline $\mathrm{Y}^{1}$ & 2045.0 & 2159.0 & 2108.2 & 2108.0 & 2132.6 & 2107.9 & 2167.5 & 2142.6 \\
\hline$Y 8^{2}$ & 2061.5 & 2174.0 & 2123.4 & 2118.1 & 2155.8 & 2124.0 & 2178.5 & 2153.6 \\
\hline $\mathrm{Y}^{1}$ & 2077.0 & 2189.4 & 2134.0 & 2136.0 & 2171.2 & 2136.4 & 2193.5 & 2166.5 \\
\hline $\mathrm{Y}^{2}$ & 2095.5 & 2205.0 & 2150.5 & 2153.3 & 2185.4 & 2152.5 & 2209.0 & 2182.0 \\
\hline \multirow{3}{*}{ position } & Ningdong & Ningdong & Ningdong & Ningdong & Ning & Ningdong & Ningdong & Ningdong \\
\hline & $2-3$ & $2-4$ & $2-5$ & $2-6$ & 3 & 9 & 106 & 108 \\
\hline & $\begin{array}{c}\text { Head } \\
\text { depth }(\mathrm{m})\end{array}$ & $\begin{array}{c}\text { Head } \\
\text { depth }(\mathrm{m})\end{array}$ & $\begin{array}{c}\text { Head } \\
\text { depth }(\mathrm{m})\end{array}$ & $\begin{array}{c}\text { Head } \\
\text { depth }(m)\end{array}$ & $\begin{array}{c}\text { Head } \\
\text { depth }(\mathrm{m})\end{array}$ & $\begin{array}{c}\text { Head } \\
\text { depth }(\mathrm{m})\end{array}$ & $\begin{array}{c}\text { Head } \\
\text { depth }(\mathrm{m})\end{array}$ & $\begin{array}{c}\text { Head } \\
\text { depth }(\mathrm{m})\end{array}$ \\
\hline$Y 8^{1}$ & 2177.60 & 2209.00 & 2142.64 & 2110.47 & 2136.00 & 2152.48 & 2153.00 & 2150.00 \\
\hline$Y 8^{2}$ & 2187.30 & 2219.20 & 2153.40 & 2126.30 & 2153.40 & 2164.00 & 2170.50 & 2163.00 \\
\hline$Y 9^{1}$ & 2202.60 & 2231.80 & 2166.49 & 2140.58 & 2172.00 & 2184.00 & 2195.94 & 2179.50 \\
\hline $\mathrm{Y}^{2}$ & 2218.20 & 2253.70 & 2186.30 & 2161.10 & 2185.50 & 2196.80 & 2209.00 & 2198.10 \\
\hline \multirow{3}{*}{ Position } & Ningdong & Ningdong & Ningdong & Ningdong & Ningdong & Ningdong & Ningdong & Ningdong \\
\hline & 3-1 & 3-2 & 3-3 & 3-4 & 3-5 & 3-6 & 3-7 & 3-8 \\
\hline & $\begin{array}{c}\text { Head } \\
\text { depth }(\mathrm{m})\end{array}$ & $\begin{array}{c}\text { Head } \\
\text { depth }(m)\end{array}$ & $\begin{array}{c}\text { Head } \\
\text { depth }(m)\end{array}$ & $\begin{array}{c}\text { Head } \\
\text { depth }(m)\end{array}$ & $\begin{array}{c}\text { Head } \\
\text { depth }(m)\end{array}$ & $\begin{array}{c}\text { Head } \\
\text { depth }(\mathrm{m})\end{array}$ & $\begin{array}{c}\text { Head } \\
\text { depth }(m)\end{array}$ & $\begin{array}{c}\text { Head } \\
\text { depth }(\mathrm{m})\end{array}$ \\
\hline $\mathrm{Y}^{1}$ & 2198.30 & 2214.50 & 2236.48 & 2148.00 & 2146.50 & 2168.80 & 2159.20 & 2133.20 \\
\hline$Y 8^{2}$ & 2213.30 & 2231.00 & 2256.70 & 2162.00 & 2154.87 & 2185.70 & 2172.30 & 2156.96 \\
\hline$Y 9^{1}$ & 2231.00 & 2251.01 & 2273.10 & 2179.00 & 2172.00 & 2202.83 & 2190.50 & 2172.80 \\
\hline$Y 9^{2}$ & 2242.00 & 2265.50 & 2295.50 & 2192.00 & 2189.00 & 2218.60 & 2208.20 & 2190.20 \\
\hline \multirow{3}{*}{ Position } & Ningdong & Ningdong & Ningdong & Ningdong & Ningdong & Ningdong & Ningdong & Ningdong \\
\hline & 3-9 & $3-10$ & $3-11$ & 17 & $17-1$ & $17-2$ & $17-3$ & $17-4$ \\
\hline & $\begin{array}{c}\text { Head } \\
\text { depth }(\mathrm{m})\end{array}$ & $\begin{array}{c}\text { Head } \\
\text { depth }(m)\end{array}$ & $\begin{array}{c}\text { Head } \\
\text { depth }(m)\end{array}$ & $\begin{array}{c}\text { Head } \\
\text { depth }(m)\end{array}$ & $\begin{array}{c}\text { Head } \\
\text { depth }(\mathrm{m})\end{array}$ & $\begin{array}{c}\text { Head } \\
\text { depth }(\mathrm{m})\end{array}$ & $\begin{array}{c}\text { Head } \\
\text { depth }(\mathrm{m})\end{array}$ & $\begin{array}{c}\text { Head } \\
\text { depth }(\mathrm{m})\end{array}$ \\
\hline $\mathrm{Y}^{1}$ & 2145.90 & 2141.35 & 2171.40 & 2127.42 & 2160.00 & 2186.09 & 2183.66 & 2200.54 \\
\hline $\mathrm{Y} 8^{2}$ & 2158.48 & 2158.70 & 2189.63 & 2146.30 & 2178.00 & 2209.60 & 2199.18 & 2218.27 \\
\hline$Y 9^{1}$ & 2175.87 & 2193.10 & 2224.11 & 2169.17 & 2202.00 & 2233.22 & 2222.30 & 2242.15 \\
\hline$Y 9^{2}$ & 2192.20 & 2174.09 & 2205.81 & 2181.39 & 2217.60 & 2243.56 & 2235.01 & 2256.78 \\
\hline
\end{tabular}

Table 5. Comparison results of small layer divide and comparison of Yan 8 and Yan 9 groups in Ningdong 5 well area.

\begin{tabular}{cccccccccc}
\hline & $\begin{array}{c}\text { Ningdong } \\
5\end{array}$ & Ningdong & Ningdong & Ningdong & Ningdong & Ningdong & \multicolumn{2}{c}{ Ningdong } & Ningdong \\
Position & 10 & 105 & $105 \mathrm{~K}$ & $5-1$ & $5-2$ & $5-4$ \\
\cline { 2 - 9 } & $\begin{array}{c}\text { Head } \\
\text { depth }(\mathrm{m})\end{array}$ & $\begin{array}{c}\text { Head } \\
\text { depth }(\mathrm{m})\end{array}$ & $\begin{array}{c}\text { Head } \\
\text { depth }(\mathrm{m})\end{array}$ & $\begin{array}{c}\text { Head } \\
\text { depth }(\mathrm{m})\end{array}$ & $\begin{array}{c}\text { Head } \\
\text { depth }(\mathrm{m})\end{array}$ & $\begin{array}{c}\text { Head } \\
\text { depth }(\mathrm{m})\end{array}$ & $\begin{array}{c}\text { Head } \\
\text { depth }(\mathrm{m})\end{array}$ & $\begin{array}{c}\text { Head } \\
\text { depth }(\mathrm{m})\end{array}$ \\
\hline $\mathrm{Y}^{1}$ & 2273.2 & 2309.5 & 2150.9 & 2277.6 & 2290.0 & 2323.8 & 2367.0 & 2307.3 \\
$\mathrm{Y}^{2}$ & 2287.5 & 2323.7 & 2168.0 & 2292.3 & 2304.0 & 2337.2 & 2383.0 & 2332.5 \\
$\mathrm{Y9}^{1}$ & 2307.5 & 2341.5 & 2184.4 & 2312.0 & 2325.0 & 2355.2 & 2401.0 & 2351.8 \\
$\mathrm{Y9}^{2}$ & 2322.0 & 2356.9 & 2200.0 & 2328.8 & 2341.5 & 2373.2 & 2416.7 & 2365.7 \\
\hline
\end{tabular}


Continued

\begin{tabular}{ccccccccc}
\hline & $\begin{array}{c}\text { Ningdong } \\
\text { P-4K }\end{array}$ & $\begin{array}{c}\text { Ningdong } \\
5-5\end{array}$ & $\begin{array}{c}\text { Ningdong } \\
5-6\end{array}$ & $\begin{array}{c}\text { Ningdong } \\
5-8\end{array}$ & $\begin{array}{c}\text { Ningdong } \\
5-9\end{array}$ & $\begin{array}{c}\text { Ningdong } \\
5-11\end{array}$ & $\begin{array}{c}\text { Ningdong } \\
5-12\end{array}$ & Ningdong \\
\cline { 2 - 9 } & $\begin{array}{c}\text { Head } \\
\text { depth }(\mathrm{m})\end{array}$ & $\begin{array}{c}\text { Head } \\
\text { depth }(\mathrm{m})\end{array}$ & $\begin{array}{c}\text { Head } \\
\text { depth }(\mathrm{m})\end{array}$ & $\begin{array}{c}\text { Head } \\
\text { depth }(\mathrm{m})\end{array}$ & $\begin{array}{c}\text { Head } \\
\text { depth }(\mathrm{m})\end{array}$ & $\begin{array}{c}\text { Head } \\
\text { depth }(\mathrm{m})\end{array}$ & $\begin{array}{c}\text { Head } \\
\text { depth }(\mathrm{m})\end{array}$ & $\begin{array}{c}\text { Head } \\
\text { depth }(\mathrm{m})\end{array}$ \\
\hline $\mathrm{Y}^{1}$ & 2285.3 & 2315.0 & 2263.4 & 2205.0 & 2217.0 & 2292.2 & 2286.3 & 2186.4 \\
$\mathrm{Y}^{2}$ & 2298.5 & 2328.2 & 2274.5 & 2217.9 & 2228.6 & 2325.0 & 2316.2 & 2199.1 \\
$\mathrm{Y9}^{1}$ & 2319.2 & 2342.2 & 2293.6 & 2236.8 & 2251.0 & 2275.0 & 2270.6 & 2237.5 \\
$\mathrm{Y9}^{2}$ & 2338.3 & 2359.2 & 2312.6 & 2253.2 & 2264.6 & 2308.9 & 2300.7 & 2220.7 \\
\hline
\end{tabular}

\subsection{The Difference between the Division Result and the Original Hierarchical Data}

After re-dividing and comparing Ningdong 2, 3 and 5 well areas, the division and comparison results of the old wells are basically the same as those of the previous project. In addition, the new wells are divided into large and small layers. Ningdong 2 and 3 well areas mainly include the following 7 new wells: Ningdong 3-8, Ningdong 3-11, Ningdong 17, Ningdong 17-1, Ningdong 17-2, Ningdong 17-3, and Ningdong, Ningdong 5 well area mainly includes the following 5 new wells: Ningdong 5-8, Ningdong 5-9, Ningdong 5-11, Ningdong 5-12, and Ningdong 5-13.

The difference between the reservoir stratification and the original stratification data in Ningdong 2 and 3 well areas is mainly in the extension 2 layer, and the extension 2 layer has an obvious coal seam marker layer, which should be divided into the top boundary of extension 2 by the coal seam top. The collected new well extension 2 is not divided into the top boundary of the coal seam. In this study, the top boundary of extension 2 is divided into the top boundary of the coal seam, and, the change is not big, and the difference between the top and bottom is not more than 1 meter, so it has little impact on the stratification, basically according to the unit standard.

The difference between reservoir stratification and original stratification in Ningdong 5 well area is mainly in the extension 8 layer. There is a relatively obvious coal seam marker layer in the extension 8 top boundary of the well area. The original stratification is divided into mudstone sections above the coal seam. This time, extension 8 of the newly collected new well is divided into the top of the coal seam. The division mark of small layers is relatively obvious, basically according to the standard of the unit.

The above is mainly the difference between the division and comparison results of the new well and the originally collected data (Table 6, Table 7, Figure 17, Figure 18).

Table 6. Comparison table of stratigraphic division and original stratification data in well areas 2 and 3 of Ningdong.

\begin{tabular}{ccccccc}
\hline \multirow{2}{*}{ Well number } & \multicolumn{5}{c}{ Head depth (m) } \\
\cline { 2 - 6 } Position & Ningdong & Ningdong & Ningdong & Ningdong & Ningdong & Ningdong \\
& $3-8$ & $3-11$ & 17 & $17-1$ & $17-2$ & $17-3$ \\
\hline Yan 2 & $1937.1 / 1926$ & $1959.4 / 1951.4$ & $1950.4 / 1929.3$ & $1957.2 / 1938.4$ & 1970.99 & 1969.63 \\
Yan 8 & & $2176.5 / 2167.5$ & & & \\
\hline
\end{tabular}




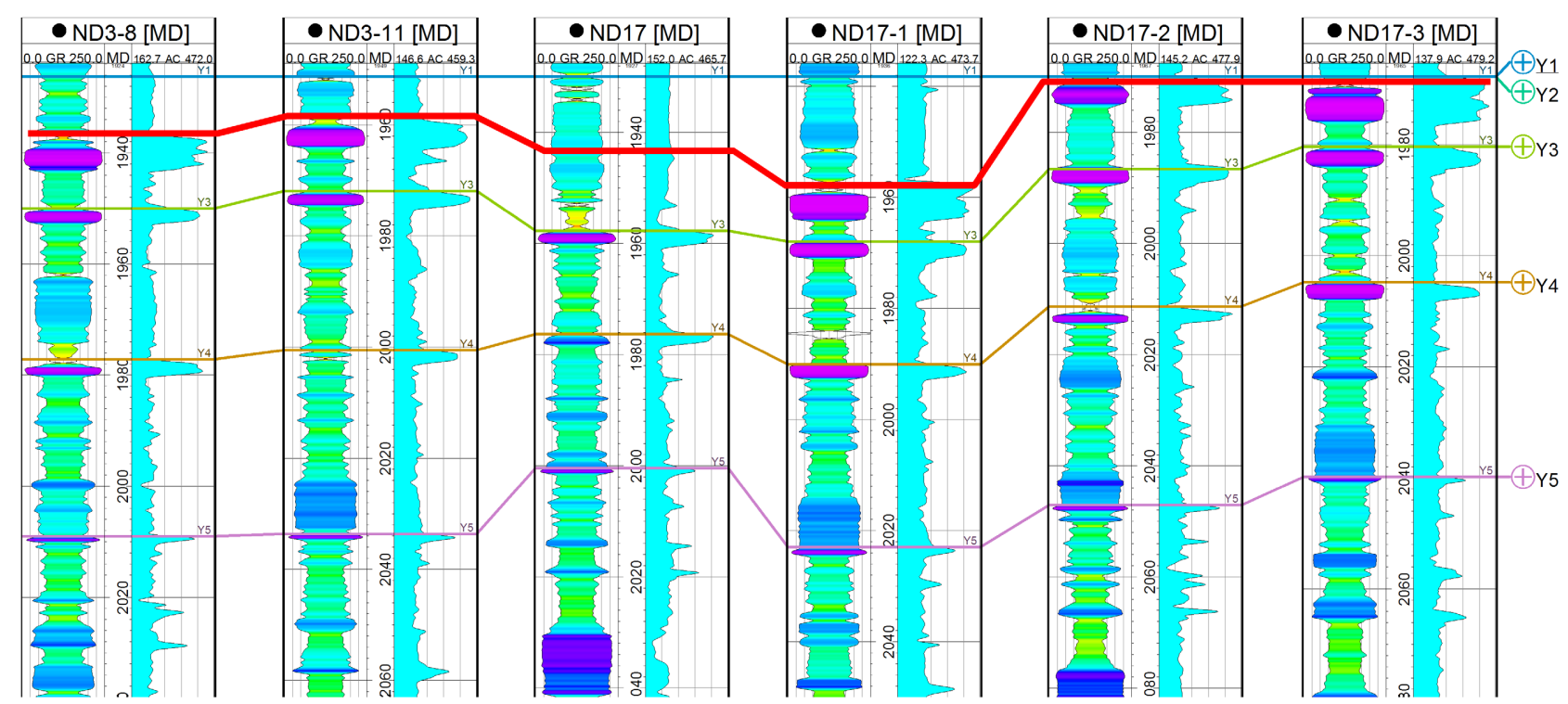

Figure 17. The difference between the unit stratification results of the 2-layer group in Ningdong 2 and 3 well areas and this stratification results (The red thick line is the result of this layering).

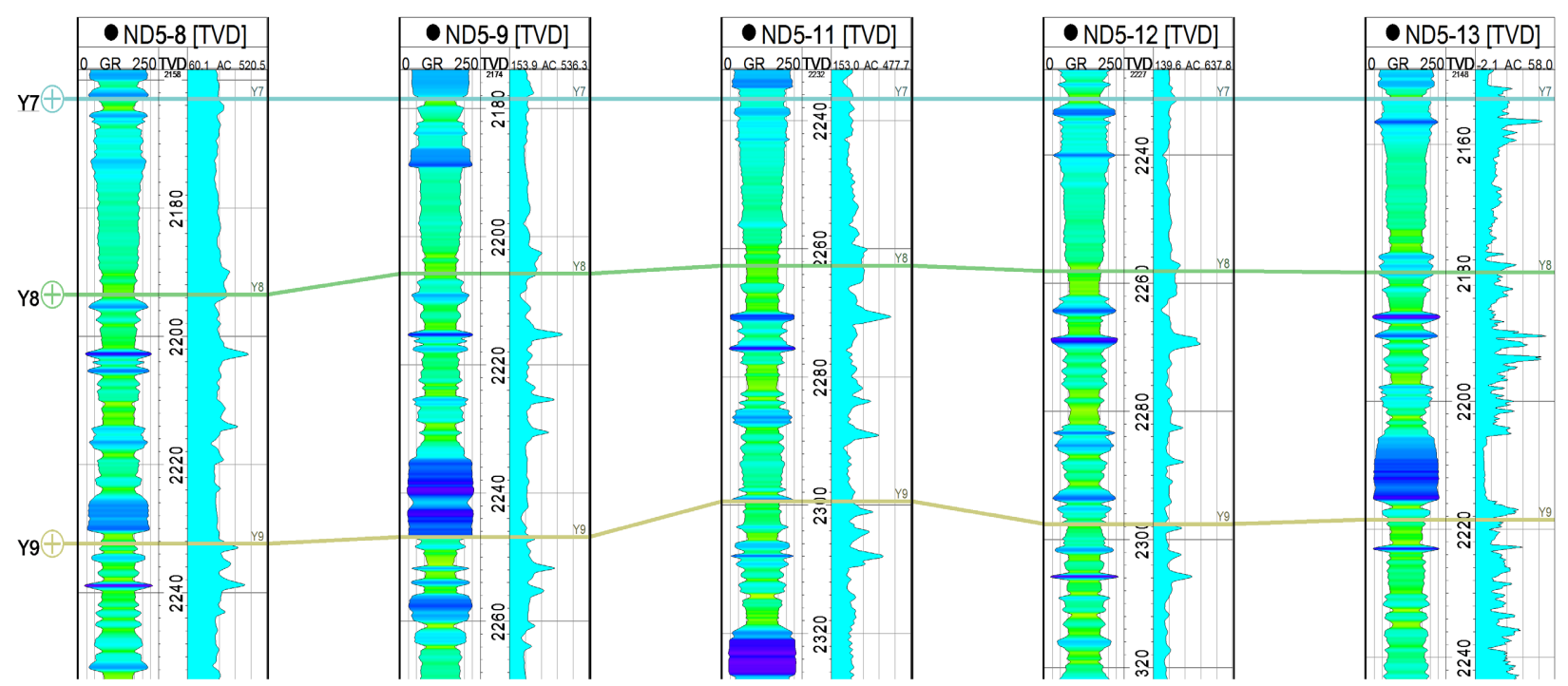

Figure 18. Difference between the stratification results of 8 units in Ningdong well area and this stratification results (The red thick line is the result of this layering).

Table 7. Comparison table of new well stratum division and original stratification data in Ningdong 5 well area.

\begin{tabular}{cccccc}
\hline \multirow{2}{*}{ Well number } & \multicolumn{5}{c}{ Head depth $(\mathrm{m})$} \\
\cline { 2 - 6 } Position & Ningdong & Ningdong & Ningdong & Ningdong & Ningdong \\
& $5-8$ & $5-9$ & $5-11$ & $5-12$ & $5-13$ \\
\hline Yan 8 & $2205 / 2193$ & $2216.5 / 2205.8$ & 2276.5 & 2271 & 2186.4 \\
\hline
\end{tabular}

\section{Conclusion}

1) Using Petrel software, according to the cycle of sedimentary evolution, the Yan 1, Yan 2, Yan 3, Yan 4 +5, Yan 6, Yan 7, Yan 8, Yan 9, Yan 10 of the west- 
ern block of Mahuangshan Oilfield are divided and compared. Among them, the Yan 8 and Yan 9 oil formation groups are based on the original stratification and re-according to the concept of isochronous stratigraphic units, the Yan 8 oil layer is divided into two time stratigraphic units, Yan 81 and Yan $8^{2}$, and the Yan 9 oil layer group is divided into two time stratigraphic units, Yan $9^{1}$ and Yan $9^{2}$.

2) After analysis, there are 4 obvious marker layers in the western block of Mahuangshan Oilfield. The top coal seam of Yan 2 is thicker, most wells can be compared, and the distribution is wide and stable. The electrical characteristics of the top coal seam are obvious, which is characterized by low gamma, low density, high resistance, high time difference and high voltage. The most obvious sign layer in the whole area is the mark layer 1; the electrical characteristics of the top coal seams of Yan 3, Yan $4+5$ and Yan 10 are more obvious, and the distribution is relatively stable, they are marker layers 2, 3 and 4 respectively.

3) The results of division and comparison are basically the same as those of the previous project. The stratification results of Ningdong 2 and 3 well area extension 2 and Ningdong 5 well area extension 8 are mainly changed. Ningdong 2, 3 well area extension 2 layers at the top of the sign layer coal seam, Ningdong 5 well area extension 8 layer at the top of the auxiliary sign layer coal seam, some of the well stratification up and down also moved, but the movement results are very small, most of them are about $0.5 \mathrm{~m}$, does not affect the stratification results.

\section{Conflicts of Interest}

The authors declare no conflicts of interest regarding the publication of this paper.

\section{References}

[1] Hao, Y. (2008) Sequence Stratigraphy and Reservoir Sand Body Characteristics of Middle Jurassic Yan'an Formation in Mahuang Shanxi Area, Ordos Basin. Chengdu University of Technology, Chengdu.

[2] Yan, J.P. and Lv, Y.J. (2009) Analysis of Fault Structure Characteristics and Hydrocarbon Accumulation in Mahuang Shanxi Area. Petroleum Geology and Engineering, 23, 15-17.

[3] Li, W.S., Ma, G.S., Wei, D., Mao, J.W. and Yang, Y. (2011) Sedimentary Facies Analysis of Yan 8 - 10 Layers of Yan'an Formation in Mahuang Shanxi Area, Ordos Basin. Shaanxi Geology, 29, 47-55.

[4] Tao, Y. (2009) Reservoir Characteristics and Evaluation of Yan'an Formation in the Northeast of Mahuang Shanxi Block. Chengdu University of Technology, Chengdu.

[5] Chen, Z.Y. (2010) 3D Reservoir Modeling of Jurassic Yan 8 Formation in Ningdong 2 and 3 Well Blocks of Mahuang Shanxi block, Ordos Basin. Journal of Paleogeography, 12, 346-354.

[6] Wen, L., Leng, G.F. and Sun, H.T. (2010) Technical Method of Sub Layer Division and Correlation. Inner Mongolia Petrochemical Industry, 36, 104-105.

[7] Yang, L. (2008) Restoration of Jurassic Yan'an Primitive Basin in Ordos Basin. 
Northwest University, Xi'an.

[8] Huang, J. (2008) Study on Management Countermeasures of High-Yield Wells in Fractured Vuggy Reservoirs. China University of Petroleum, Beijing.

[9] Jia, B. (2015) Study on Reservoir Characteristics and Oil and Gas Enrichment Law of Chang $4+5$ Oil Formation in Yougou Oil Area of Wuqi Oilfield. Chang'an University, Xi'an.

[10] Liu, B.Y. (2017) Study on Enrichment Law of Yan 9 Reservoir in Jiyuan Oilfield. Xi'an University of Petroleum, Xi'an.

[11] Zhang, Y.F. (2013) Study on Geological Conditions and Reservoir Forming System of CO Enrichment of Multiple Energy Minerals in Ordos Basin. China University of Geosciences, Beijing.

[12] Hou, S.W. (2009) Yan 8, Mahuang Mountain, Ordos Basin. Comparative Study on Fine Division of Oil Reservoir Groups. Inner Mongolia Petrochemical Industry, 35, 122-124. 